\title{
Identidad emocional y tertulias televisivas en el contexto político de Catalunya
}

\section{Identitate emozionala eta telebistako solasaldiak Kataluniako testuinguru politikoan}

\section{Emotional identity and TV talk-shows in the political context of Catalonia}

\section{Laura Santamaria Guinot ${ }^{1}$}

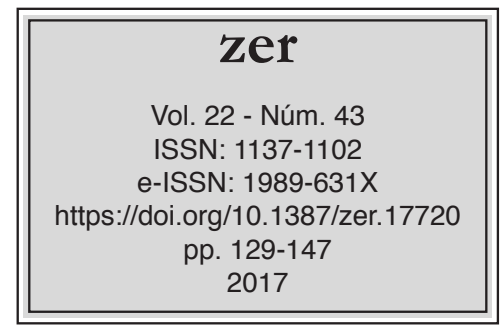

Recibido el 27 de marzo de 2017, aceptado el 30 de septiembre de 2017.

\section{Resumen}

A partir del análisis de dos tertulias televisivas del programa Divendres de Televisió de Catalunya, este artículo muestra cómo los participantes presentan su punto de vista a partir de recreación de unas emociones determinadas. Estas emociones tienen múltiples vertientes: se pueden discriminar en ellas unos componentes afectivos, cognitivos, conativos y psicológicos; muestran a la vez estados cualitativos, pero también racionales; se relacionan con conceptos como las representaciones sociales, la memoria y la identidad. Es así como se configura una identidad discursiva que la cámara termina perfilando en un sentido concreto.

Palabras clave: Emotivismo, identidad periodística, discurso, multimedia, televisión, debate.

\section{Laburpena}

Televisió de Catalunya-ko Divendres programako bi solasaldiren azterketatik abiatuta, artikulu honek erakusten du solaskideek norberaren ikuspegia emozio jakin batzuk birsortzetik aurkezten dutela. Emozio horiek alderdi asko dituzte: badituzte emozio horiek osagai afektiboak, kognitiboak, konatiboak eta psikologikoak; aldi berean egoera kualitatiboak ageri dituzte, baina baita arrazionalak ere; eta hainbat kontzepturekin lotzen dira, hala nola irudikapen sozialekin, memoriarekin eta identitatearekin. Horrela taxutzen da identitate diskurtsibo bat; azken ukitua kamerak ematen dio, zentzu zehatz batean.

\footnotetext{
Universitat Autònoma de Barcelona, laura.santamaria@uab.cat
} 
Gako-hitzak: Emotibismoa, kazetariaren identitatea, diskurtsoa, multimedia, telebista, debatea.

\begin{abstract}
Based on the analysis of two television talk shows in the program Divendres of Televisió de Catalunya, this article shows how the talk-show guests present their point of view from the recreation of certain emotions. These emotions have multiple aspects: affective, cognitive, conative and psychological components can be discriminated; both qualitative but also rational states can be categorized; they are related to concepts such as social representations, memory and identity. This is how a discursive identity is configured and the camera ends up defining it in a concrete sense.
\end{abstract}

Keywords: Emotions, media identity, discourse, multimedia, television, debate. 


\section{Introducción}

En este trabajo queremos observar cómo los participantes en dos debates televisivos en Televisió de Catalunya hacen uso del discurso emotivo y de qué manera los espectadores les confieren una identidad discursiva a partir de las emociones que se observan. El objetivo es relacionar las emociones que se generan durante los debates televisivos con las identidades emotivas de los tertulianos que intervienen en los mismos.

Las preguntas que queremos responder son dos:

¿Qué uso del discurso emotivo hacen los participantes de la tertulia-debate?

¿Qué identidad discursiva les confiere este discurso emotivo?

\section{Caracterización de los programas analizados}

Las tertulias de este estudio forman parte del programa de sobremesa de Televisió de Catalunya Divendres. La primera fue conducida por Xavier Coral el martes 26 de noviembre de 2013 y la segunda el 7 de marzo de 2016 por Helena García Melero, quien se hizo cargo del programa a partir de septiembre de 2015. Suelen participar en estas tertulias personalidades habituales que provienen tanto del mundo académico como de los medios de comunicación y en ellas se debaten temas de actualidad.

En la primera, la discusión gira en torno al proceso de autodeterminación y concretamente sobre la dificultad de los partidos para formular un enunciado que tenga suficiente consenso para convertirse en la pregunta que deberá responder en la Consulta sobre la independencia de Catalunya. Finalmente, la pregunta y fecha de la consulta se hicieron públicas el 12 de diciembre de 2013. Durante el debate Juan Carlos Girauta presenta el libro que acaba de publicar, Votaré no a la secesión de Cataluña. En la segunda tertulia los participantes debaten, desde la perspectiva catalana, las dificultades para poder formar gobierno en Madrid tras las elecciones del 20 de diciembre de 2015.

Los colaboradores en la primera tertulia son Manuel Cuyàs, historiador y director de El Punt; Vicent Sanchis, periodista ex director de la revista El Temps y del diario Avui, que se acaba de hacer cargo de la dirección de Televisió de Catalunya en el 2017; Juan Carlos Girauta, periodista y analista político; Xavier Sardà, periodista director de programas de radio y televisión; Pere Mas, periodista de radio y televisión; y Tian Riba, guionista del programa, y colaborador habitual de la prensa y la radio.

Los participantes en el segundo debate son Francesc Romeu, rector de la parroquia de Santa María del Taulat y Sant Bernat en Poblenou (Barcelona) y profesor de Periodismo en la Universidad Ramon Llull; Núria Ferré, presentadora y editora de informativos y de varios programas de radio y de televisión, es colaboradora habitual del programa Divendres desde 2010; Sebastià Serrano, lingüista y catedrático de lingüística general en la Universidad de Barcelona, tiene varias publicaciones sobre la comunicación no verbal y su influencia en las relaciones humanas; Manel Manchón es el director de Economía Digital, ha trabajado en el diario Ara y en el Periódico de Cataluña y fue responsable de Comunicación del Departamento de Economía de la Generalitat entre 2009 y 2010; y Tian Riba.

La tertulia del primer programa duró unos tres cuartos de hora y se analizó de manera completa. De la segunda solo se ha tenido en cuenta la primera 
media hora en la que se debate el tema „Comienza la cuenta atrás para evitar que haya elecciones", título que aparece frecuentemente como inserto durante los primeros treinta minutos, ya que en el cuarto de hora restante se produce un cambio de tema, la crisis en Europa a partir de la llegada de refugiados. Las conclusiones del análisis de las emociones que se muestran en la primera tertulia las presentaron la autora de este artículo y la profesora de la Facultad de Ciencias de la Comunicación de la UAB Anna Torrent el 8 de octubre de 2014 en la Jornada identitat(s) a Catalunya, promovida por el grupo Llengua i Mèdia de la UAB y el Instituto de la Comunicación de la misma Universidad, con el objetivo de reflexionar alrededor del concepto de identidad desde varios puntos de vista. En la preparación de este artículo se ha añadido el análisis de la segunda tertulia. En el primer debate los tertulianos estaban divididos entre unionistas e independentistas, había por tanto una distinción entre „,nosotros“ y „ellos“ dentro de Catalunya. En la segunda, la división entre „,nosotros“ y ,ellos“ se refiere a Catalunya y España. Los programas se emitieron en unas fechas decisivas en el "proceso" catalán, es decir en dos momentos de atasco político, por lo que se consideró que los participantes mostrarían una imagen identitaria determinada, lo cual se ha podido evidenciar en el análisis. El tema de la primera tertulia se centra en si será posible que las fuerzas secesionistas acuerden una pregunta para la consulta que finalmente se llevó a cabo el 9 de noviembre de 2014. Esta incapacidad de los políticos catalanes para llegar a un acuerdo ocasionó una gran tensión que los medios recogieron. La imposibilidad de crear un diálogo también está presente en la segunda tertulia, pero referido a los políticos del Estado español, quienes aparecen en la misma como incapaces de llegar a un acuerdo por su falta de destreza para dialogar, una inhabilidad que se ha convertido en una representación social compartida por buena parte de la sociedad catalana a través de los años. Podemos decir que hay una evolución del concepto identitario catalán y es precisamente este desarrollo lo que queremos estudiar desde la perspectiva emocional.

Como el papel del conductor del programa es dirigir la tertulia hacia los temas que se quieren debatir en público no analizaremos las intervenciones ni de Xavier Coral ni de Helena Garcia Melero.

\section{Caracterización de las emociones}

Por un lado, partimos de la premisa de que existe una cierta relación entre las emociones que se generan en los medios de comunicación y en las situaciones cotidianas. Si como espectadores somos capaces de procesar información es porque tenemos unas herramientas aprendidas socialmente (en el sentido de disposiciones de Bourdieu).

Wirth y Schramm (2005: 4) disciernen en las emociones los componentes siguientes, que relacionaremos con los programas analizados:

- Afectivo. La vertiente afectiva de las emociones está basada en las experiencias subjetivas de situaciones que provocan sentimientos de satisfacción e insatisfacción, en grados distintos. En nuestro caso, se trata de unas tertulias televisivas en un magazine de sobremesa. El espectador que se plantea seguir el programa es conocedor de los límites que 
marcan el medio y el presentador a los tertulianos con respecto a su comportamiento comunicativo, y las expectativas que la audiencia tiene son enriquecer su conocimiento, a partir de la recepción de diversos puntos de vista sobre un tema de interés -obtención de una gratificación eudaimónica-, pero también la de entretenerse asistiendo a una sesión emocionalmente intensa, por la personalidad y adscripción ideológica de los tertulianos -obtención de una gratificación hedonista- (Roth et al., 2010).

- Cognitivo. Las emociones son percibidas y evaluadas por los sujetos. En la situación comunicativa del debate televisivo de sobremesa, hay que esperar que los espectadores comprendan el discurso emotivo de los tertulianos y lo evalúen, tanto por su comportamiento discursivo en el programa analizado como por lo recuerdan de su intervención en capítulos anteriores del programa Divendres, o en la de otros programas de TV3, o de otros medios. El conocimiento que tienen los espectadores de la realidad televisiva, gracias a los recuerdos guardados en la memoria, como veremos más adelante, acaban confiriendo un valor determinado a cada interlocutor.

- Conativo. El componente conativo está relacionado con el comportamiento expresivo de los debatientes - que va más allá de la propia palabra, porque está matizado por los movimientos y la gestualidad-, con el que tratan de obtener la adhesión pasional de los interlocutores y de la audiencia. Este es el componente, pues, que podrá ser más capitalizado y modificado por la mirada de la cámara, sobre todo porque se convierte en la clave que guía a los espectadores hacia una lectura concreta.

- Psicológico. Las emociones generan reacciones periféricas al cuerpo, mediadas por el sistema nervioso. Si bien no nos proponemos analizar las emociones desde este punto de vista en este trabajo, sí que tendremos en cuenta el hecho de que el discurso de los tertulianos va acompañado, a veces, de determinadas expresiones faciales o de ciertos movimientos corporales, que denotan emociones diversas, como impaciencia o irritación. Sin embargo, creemos que todo ello debe abordarse con mucha cautela, ya que somos conscientes de que la cámara querrá exagerar esas emociones en algunos casos -ofreciendo un primer plano, por ejemplo-, mientras que en otras ocasiones preferirá disimularlos - no enfocando al tertuliano o enfocándolo de lejos-.

\section{Emociones, representaciones sociales, memoria e identidad}

La capacidad de comprensión se activa si los espectadores son capaces de relacionar los enunciados, en el sentido más amplio del término, con unas representaciones sociales. De acuerdo con Abric (1984), la representación puede definirse como la totalidad de información, creencias, actitudes y opiniones que el individuo adquiere 
con relación a un objeto determinado. Es decir, cada uno de los espectadores deriva la información que proviene de la totalidad del enunciado, a partir de una serie de conocimientos previos. La memoria juega un papel destacado, ya que los espectadores deben inferir el significado de los enunciados, que incluyen también información sobre las emociones. Además, tal como Squire (2001) afirma, existen ciertos límites y posibilidades para comunicar las emociones en los medios y concretamente en las tertulias televisivas. Las fronteras de la presencia tolerada de emociones es una representación social más y por ello se recurre a la memoria que actúa como instrumento que permite la inferencia de la totalidad del significado.

Al mismo tiempo, memoria e identidad van de la mano, ya que, como afirma Van Dijk (1998), la identidad es tanto un constructo personal como social, es decir, se trata de una representación social de la memoria personal (episódica). Observamos, pues, que los cuatro conceptos, enunciado, memoria, representación social e identidad, están estrechamente relacionados en las emociones.

La relación que forjan los medios entre estos elementos es bastante compleja. Los individuos han generado unas representaciones sociodiscursivas de unas identidades sociales que, según Tajfel (1981), deben entenderse como una parte del concepto que de sí mismo posee el individuo y que deriva del conocimiento que tiene sobre su pertenencia a un grupo social (o a unos grupos sociales) junto con el valor y la significación emocional unidos a esta pertenencia. Precisamente, es en este comportamiento social donde tienen un papel relevante las emociones. En concreto, como dice Walton (1992), podemos afirmar que la situación comunicativa -en este caso, el debate televisivo- conforma el discurso.

También Charaudeau (2011) habla del carácter social de las emociones: estas permiten garantizar ,una cohesión social“ y „un sentimiento de pertenencia al grupo“. Tienen, pues, un valor ideológico y no es de extrañar, en consecuencia, que los colaboradores en las tertulias utilicen las emociones como efectos de discurso, para llevar el agua hacia su molino:

Las emociones no conciernen solamente a la pulsión, lo irracional y lo incontrolable, sino que tienen también un carácter social. En este sentido, las emociones serían el garante de la cohesión social, permitirían al individuo constituir su sentimiento de pertenencia a un grupo, representarían la vitalidad de la conciencia colectiva. Esto quiere decir que, al ser signo de reconocimiento para los miembros de un grupo, descansan sobre un juicio colectivo que instituye una especie de regla moral. Infringir la regla conllevar una sanción (Durkheim), lo que en contrapartida da a esos juicios un carácter de obligación (Charaudeau, 2011: 97).

En consecuencia, las emociones que reflejan los hablantes manifiestan su adscripción a un grupo social; en el caso de la tertulia analizada alrededor del llamado "proceso", aparecen sobre todo dos adscripciones polarizadas: la del constitucionalismo/ españolismo y la del independentismo/catalanismo, con matizaciones diversas. Cada tertuliano defiende el juicio colectivo de su grupo, pero lo respalda en una situación 
(programa televisivo) en que debe respetar la regla de mostrarse como un ciudadano que opina, y no como un representante político. En este sentido, se puede interpretar la reacción indignada de Girauta cuando niega rotundamente que pertenezca al partido Ciudadanos (a los pocos meses se hacía oficial su candidatura a las elecciones europeas por este partido). En la segunda tertulia el debate se centra en los motivos que no permiten que los partidos se pongan de acuerdo para formar gobierno en Madrid. También se emiten juicios acerca de cómo los „nuestros“, "los políticos catalanes" consiguieron desatascar la composición de gobierno después de un callejón sin salida de un par de meses durante los cuales los partidos estuvieron negociando sobre cómo se debía llevar a cabo la votación para nombrar al presidente de la Generalitat y las razones que dificultan que ,ellos“, los parlamentarios españoles, se pongan de acuerdo.

Debemos prever que descubriremos unas emociones que actuaran ,como efectos del discurso", como dice Charaudeau (2009), para captar la atención de la audiencia y dar credibilidad a las creencias que quiere difundir el tertuliano y que comparte con su grupo social. Por ello, cabe esperar que el tertuliano intentará presentar sus argumentos, no como un punto de vista propio, sino como una parte del conocimiento compartido con otros hablantes. Fijémonos en que, con relación al conocimiento, el mismo Charaudeau lo distingue de las creencias, en tanto que el conocimiento se fundamenta en criterios de verdad externos al sujeto, mientras que las creencias son propias del sujeto y compartidas sólo por el grupo en el que se integra. Si esta relación se consigue mostrar como compacta, cada uno de los tertulianos puede representar unas emociones determinadas „,como interpretación de las circunstancias“, ya que „(1) ,identité este donc une affaire complexe, car elle n>est pas seulement l'affaire de soi, mais aussi l'affaire des autres, on plus exactement, l'affaire de soi à travers le regard de autres" (Charaudeau, 2009: 4). A partir de Bassols y Cros (2014), Chauradeau (2009) y Tresserras (2013), podemos afirmar que las identidades de los individuos son electivas, ya que las identidades son en sí mismas dinámicas y complejas porque evolucionan a lo largo del tiempo y porque cada individuo puede identificarse con más de una identidad.

Si analizamos el papel de Xavier Sardà en la primera tertulia, veremos que sus enunciados no son argumentos para presentar su punto de vista, sino más bien una re-presentación de las emociones provocadas por el discurso argumental de los tertulianos que están a favor de la pregunta para la consulta que estaba en plena discusión en ese momento. En cambio, en la segunda tertulia, Sebastià Serrano se convierte en el académico que es en realidad y recibe la atención y el respeto de los cotertulianos, que le escuchan y tratan de argumentar a partir de los parámetros del profesor universitario.

Con esta metodología estableceremos la auto-presentación (Charaudeau, 2009) que de ellos mismos hacen los tertulianos, a partir de las emociones que muestran en su discurso, ya que nuestra premisa es que la identidad es un concepto colectivo, que trasciende en el discurso. Como afirman Bassols y Cros (2014) siguiendo la propuesta de Wenger (2001), ,A partir del conjunt de trets que constitueixen la identitat discursiva dels subjectes, conseqüència de les seleccions dels parlants en relació amb les maneres de prendre la paraula, amb l'organització enunciativa i amb el maneig dels imaginaris sociodiscursius, se'n determina la legitimitat que justifica el seu dret a la paraula. La identitat, doncs, és social, però es manifesta a través del discurs.“ 
La audiencia será capaz de inferir la identidad con la que se quieren presentar los tertulianos, porque, como explican Bassols y Cros (2014), "les identitats, doncs, són, en part, adquirides, ja que es basteixen a partir d'una història pròpia i uns denominadors comuns (territori, llengua, costums, valors religiosos, ètnia, etc.) aplicables a tots els membres que el formen i que els doten de l'autenticitat i la genuïnitat imprescindibles perquè hi hagi identitat (Bucholtz i Hall, 2010).“

\section{Emociones y discurso televisivo}

\subsection{Los dos tipos de emociones en el discurso}

Para clasificar las emociones que hemos ido encontrando en el discurso, tal como Charaudeau (2011: 99) discrimina, hemos tenido que distinguir entre las emociones de estado cualitativo y las emociones de estado intencional:

- Las emociones pertenecen a un „estado cualitativo“ de orden afectivo, porque se derivan de un sujeto que experimenta y resiente estados eufóricos/disfóricos relacionado con su fisiología y sus pulsiones,

- $\quad$ pero al mismo tiempo, las emociones pertenecen a un tipo racional, dado que apuntan hacia un objeto que es figurado por un sujeto que tiene una visión del mundo, que juzga ese mundo por medio de valores que constituyen un consenso social, constituyen saberes de creencia en imaginarios sociodiscursivos, que sirven como soporte disparador de un cierto estado cualitativo del sujeto y de una reacción comportamental.

Según Charaudeau (2011), este segundo tipo de emociones suele aparecer discursivamente cuando el hablante quiere seducir a los interlocutores, sobre todo cuando no está suficientemente legitimado, ya que no se encuentra en una relación de autoridad con respecto a ellos. Es entonces que intenta captarlos: o bien seduciendo con una descripción del mundo a su conveniencia y la oferta de un imaginario en el que los interlocutores serían beneficiarios; o bien conmoviendo a los mismos, mediante la emocionalización del discurso, deliberadamente dramatizado.

En ambas tertulias hemos podido observar que los tertulianos controlan las emociones que demuestran porque tienen una intención determinada, es decir, quieren llevar el agua a su molino sin dejar de ceñirse a los límites que impone el medio en el sentido que hemos mencionado anteriormente. Así, el autocontrol es una emoción de la que hacen uso los tertulianos para despertar unas emociones determinadas en los otros tertulianos y en la audiencia, a veces positivas como es la conciliación, pero a veces negativas como pueden ser el desprecio, la insatisfacción y la tensión. Los participantes, gracias al autocontrol, no crispan el ambiente de la conversación, pero pueden hacer explícito su punto de vista negativo. Un par de ejemplos los podemos ver en los siguientes enunciados de Sebastià Serrano: „En Europa hay mucha gente que vive casi de la deuda española“ o „Yo conozco gente que se ha forrado con la deuda griega." Este tertuliano muestra su insatisfacción sobre el comportamiento de algunas personas que prefieren el lucro personal a la solidaridad. De la conciliación 
al desprecio o a la provocación también parece que hay una relación clara ("I ara, això em sap greu, però crec que a Catalunya ho hem fet. A Catalunya hem fet els deures, eh?").

El control de las emociones de los tertulianos les permite presentarse con una identidad social determinada, que es comprendida por los espectadores, quienes buscan una adscripción identitaria y una gratificación hedonista, lo cual es posible gracias a las identidades que revelan los tertulianos ya que "( $\mathrm{t}$ )he emotions are presented and read in the specific context of television, and this televisual affect acts, pragmatically and effectively, to change understandings and practices around citizenship" (Squire, 2001).

\subsection{Las emociones intencionales y las trazas semiológicas}

Charaudeau (2008) afirma que se puede controlar la emoción o sobreactuarla, refiriéndose a la emoción de orden intencional, vinculada a la racionalidad y con vistas a un objetivo. En los debates mencionados, encontramos muchos ejemplos de los dos casos, el del control y el de la sobreactuación: algunos tertulianos quieren que „,no se les note la emoción“ ( si lo consiguen, o no, es otro asunto), mientras que, en cambio, otros la exageran. En la primera tertulia, hemos detectado quien explicita la percepción de „la emoción actuada“ de algún contertulio; así, Tian Riba dice, refiriéndose a Sardà: „Ahora se está riendo porque me quiere provocar“ (32:48). Una primera elección importante para mostrar u ocultar emociones se encuentra en las palabras utilizadas en el discurso, porque permiten seguir los rastros semiológicos de la emoción. Es decir, hay palabras que son neutras y otras que son más adecuadas para la expresión de estados emocionales. Por ejemplo, en el primer debate, los tertulianos usan términos ,emocionalizadores“, como trampa, mierda, paciencia, sofisma; adjetivos, desconcertado, indignado, españolista, catalanista; expresiones, como llámale como quieras!, o las interjecciones ah!, eh!, hombre! qué paradoja!, es acojonante!, no!, permíteme!, perdón, chicos!, espera!, un momento!, a menudo repetidas con insistencia, que sirven para cortar el discurso de otro tertuliano y conseguir el turno de palabra que no tienen.

Pero las palabras neutras también tienen su oportunidad de convertirse en emocionalizadoras, gracias al contexto. Así, realidad, entusiasmo, sólo [yo sólo soy federalista], una avenida!, con todo el respeto, que son palabras y enunciados en principio neutros, están cargados de emotividad, porque el contexto en que aparecen les confiere este carácter, que, además, puede ser acentuado por la intensidad con que se pronuncian.

Estas mismas afirmaciones son válidas para la segunda tertulia. Durante el debate se compara la búsqueda de socios que hacen los partidos para poder formar gobierno con el noviazgo o el ball de rams (en las fiestas locales antiguamente los hombres regalaban ramos de flores a las mujeres con las que bailaban para mostrar su predilección hacia ellas). Esta comparación socarrona lleva a mencionar conductas sexuales poco aceptadas socialmente como tener amantes, hacer tríos, o bien orgías. Otra comparación es relacionar las conversaciones entre los distintos líderes de los partidos con las reuniones de vecinos de un edificio. Pedir a los políticos que tengan un comportamiento aceptable en las declaraciones que hacen sobre los líderes de los 
otros partidos, del mismo modo que se pide cordura para poder llegar a acuerdos en una reunión „de escalera“ acentúa el rechazo sobre las declaraciones que se han oído desde que se conoció el resultado de las elecciones y hasta el momento de la tertulia, al tiempo que confiere un aire distendido, armonioso y colaborativo a la conversación de los tertulianos. Incluso existe una tercera metáfora en la comparación de las demandas de autodeterminación de Cataluña con la telefonía móvil de último modelo y el estatuto recortado con un modelo antiguo de teléfono.

Cabe señalar al mismo tiempo la potencia emocional que tienen otros elementos de comunicación, como el tono de voz, la intensidad y el ritmo de la locución, la expresión de la cara, la gestualidad, o bien la postura del cuerpo.

En cuanto al tertuliano, estos elementos configuran su retrato emocional: el tono de voz (indignado, burlón...), la intensidad y el ritmo de la locución (acentuando las palabras clave, alargándolas, ralentizando o subiendo el ritmo, la expresión de la cara (tranquilo, irritado, impaciente...), la gestualidad retenida o exagerada (las manos con movimientos tranquilos, o marcando las palabras -incluso dando golpes sobre la mesa-...), la postura del cuerpo (quieto en la silla o revolviéndose, a veces de manera involuntaria). Así, Xavier Sardà, cuando cuenta „el entusiasmo con el que se vivió en determinados sectores aquellos años de Constitucional!“", acompaña su locución enfática, marcando con las manos cada frase, histriónicamente.

Pero estos elementos también configuran el retrato emocional de los tertulianos que escuchan, que pueden manifestar sorpresa, euforia, complicidad, u otras emociones, al oír el discurso de otro cotertuliano. Por ejemplo, en el primer debate, Manuel Cuyàs, mientras escucha argumentos contrarios a los que él esgrimía, se revuelve en la silla y gesticula hasta que consigue que el moderador le dé la palabra. En ese momento, su discurso es ordenado y tranquilo, en ningún caso se desvía del objetivo, aunque otros interlocutores intervengan.

En la segunda tertulia, las miradas de los tertulianos acaban por añadir significado a sus enunciados. Tian Riba se muestra siempre cercano Manuel Manchón y cuando el tono de la conversación se acelera más de la cuenta baja la cabeza y parece que tome notas o lea lo que lleva escrito.

\subsection{El papel de la imagen en las emociones}

La cámara, como siempre en las producciones audiovisuales, juega un papel muy importante y en este trabajo queremos subrayar, como se ha dicho anteriormente, el componente conativo de las emociones que la pantalla matiza. La cámara crea una mirada propia que se impone a la del espectador. Si quiere reflejar que hay confrontación, puede acercarnos la imagen de dos tertulianos en una pantalla dividida, aunque uno de ellos esté en verdad distraído. También es capaz de subrayar o de ocultar cualquier detalle cargado de indicios si se lo propone. Una de las cuestiones que se plantea es la relación entre la banda sonora (discurso verbal, en este caso), y la banda visual (imágenes de los hablantes). Si nos atenemos a lo que dice la Compte (2009), la información difundida desde el canal audio y la difundida desde el canal vídeo pueden aparecer relacionadas de tres maneras diferentes: con redundancia, cuando la información de ambas coincide; con complementariedad, cuando la de un canal complementa la del otro; con oposición, cuando la de un canal discrepa de la 
del otro. También están las imágenes externas de trasfondo. En el segmento mostrado, va apareciendo a menudo la imagen del Parlamento de Catalunya y una urna en primer plano, donde una mano deposita una papeleta de voto: esta es la imagen de fondo más habitual. En otros segmentos de la tertulia, se ven escenas dinámicas de la cadena humana que recorrió la costa catalana el día 11 de setiembre, Diada Nacional de Catalunya, de 2013. La mayoría de imágenes son redundantes con el texto, oímos a un tertuliano y la pantalla nos lo muestra al mismo tiempo; en otras ocasiones, sin embargo, son complementarias (palabras del tertuliano, pero vemos imágenes de otros tertulianos con el mismo punto de vista); y en otros casos se muestra la oposición entre las palabras de un tertuliano y las imágenes de otro tertuliano que no coincide con el punto de vista que el primero presenta. En la segunda tertulia, la cámara está mucho más activa que en la primera. A veces acompaña a los tertulianos en un travelling circular, los muestra en un contrapicado y se dirige con celeridad hacia el tertuliano que interrumpe la conversación.

Está claro que la cámara tiene en todo ello un papel clave para destacar la vertiente emotiva de cada tertuliano. El enfoque, la proximidad o lejanía de la imagen elegida, y el hecho de que los tertulianos aparezcan solos en pantalla, atentos escuchando a quien habla o incluso a los que escuchan, aporta información sobre la adscripción de cada uno de ellos a los dos grupos enfrentados, el "nosotros" y "ellos" que establece cada espectador a partir de su propia adscripción.

\section{Clasificación de las emociones}

Tabla 1. Clasificación de las emociones según tipo e intensidad.

\begin{tabular}{|l|l|l|l|}
\hline NEGATIVAS & $\begin{array}{l}\text { INDIGNACIÓN } \\
\text { Molestia } \\
\text { Irritación } \\
\text { Contrariedad } \\
\text { Agresividad } \\
\text { Provocación } \\
\text { Desprecio } \\
\text { Indiferencia }\end{array}$ & $\begin{array}{l}\text { ANSIEDAD } \\
\text { Tensión } \\
\text { Impaciencia } \\
\text { Inquietud }\end{array}$ & $\begin{array}{l}\text { TRISTEZA } \\
\text { Decepción } \\
\text { Insatisfacción } \\
\text { DesÁNimo } \\
\text { Desconcierto }\end{array}$ \\
\hline POSITIVAS & $\begin{array}{l}\text { ALEGRÍA } \\
\text { Euforia } \\
\text { Entusiasmo } \\
\text { Ilusión } \\
\text { Satisfacción }\end{array}$ & $\begin{array}{l}\text { CALMA } \\
\text { Tranquilidad } \\
\text { Paciencia } \\
\text { Seguridad } \\
\text { Autocontrol } \\
\text { Autosuficiencia }\end{array}$ & $\begin{array}{l}\text { EMPATíA } \\
\text { Complicidad } \\
\text { Conciliación } \\
\text { Asentimiento } \\
\text { Amabilidad }\end{array}$ \\
\hline NEUTRA & SORPRESA & & \\
\hline
\end{tabular}

En este trabajo, presentaremos una clasificación propia de las emociones basada en propuestas anteriores (Russell, 1980; Lazarus, 1966 y 1993; Ortony, Clore \& Co1lins, 1998; y Bisquerra, 2003 y 2006. En general la bibliografía sobre emociones considera que hay por lo menos cuatro emociones básicas, la rabia, la ansiedad, la tristeza y la alegría, que se generan como respuesta a un comportamiento externo o 
interno (Bisquerra 2003). En cuanto a la evaluación de estas categorizaciones, hay un consenso en referirse a las emociones como positivas o negativas. Además, los diversos autores, y entre ellos Ortony et al. (1998) han visto la necesidad de combinar estas emociones básicas con otras secundarias. Bassols, Cros y Torrent (2013) también presentan este mismo punto de vista y destacan, a partir de Russell (1980) que se debe clasificar las emociones a partir de dos dimensiones, por lo que cualquier categorización debería tener en cuenta el tipo (valence) y la intensidad (arousal).

La lista de emociones de Divendres, aparece marcada por el marco mediático. En nuestra clasificación hemos distinguido las negativas, las positivas y hemos añadido una más, la sorpresa, ya que hemos considerado que se trata de una emoción neutra:

Como se puede ver, pues, hemos trabajado a partir de siete tipos de emociones básicas (indignación, ansiedad, tristeza, alegría, calma, empatía y sorpresa). Dado que hemos creído necesario marcar la intensidad (arousal) de los discursos de los tertulianos, hemos tenido que construir unas categorías de intensidad dentro de la clasificación de emociones negativas y positivas. De esta forma consideramos que la "complicidad" es la manifestación más intensa de la categoría de "empatía" y claramente la "amabilidad" es una forma más leve de "empatía", del mismo modo que "satisfacción" implica menos intensidad que "euforia". La clasificación de emociones que acabamos de presentar se ha utilizado tanto para las emociones expresadas como para las provocadas.

En cuanto al corpus, para poder analizar las emociones de cada tertuliano a lo largo de la tertulia hemos analizado los siguientes elementos: Emoción expresada, Emoción provocada, Palabra/frase emocionadora, Ritmo y entonación, Expresión y gesto, Plano y movimiento de cámara, Observaciones.

Hemos separado las emociones en dos columnas para distinguir entre la emoción de „estado cualitativo“, a las que hemos llamado también „,emociones expresadas“, y las de ,estado mental intencional“", a las cuales también nos referimos como „emociones provocadas“ en el sentido mencionado anteriormente en el punto 5.2 y definido por Charaudeau (2011: 99). Es decir, el tertuliano se puede mostrar irritado, pero su voluntad puede ser la de generar agresividad, provocar, o mostrar desprecio o bien indiferencia. Esta dualidad entre la ,emoción expresada“ y la „emoción provocada“ es, como veremos más adelante, una estrategia ampliamente utilizada en la segunda tertulia del corpus.

En la tabla de recogida de datos hemos tenido en cuenta también la palabra o frase donde descansaba la emoción, el ritmo y la entonación con que eran pronunciados los enunciados, la expresión y el gesto del hablante, así como el plano y el movimiento de la cámara. Este es un ejemplo de parrilla completada que corresponde a la primera tertulia. Como se puede observar, en algunas la diferencia entre la emoción expresada y la provocada es solo de intensidad, pero en algunos casos pertenecen a emociones distintas.

En la primera tertulia, la emoción más generalizada es la indignación (37\%) y tiene dos vertientes, el enojo (56\%), como emoción expresada y la confrontación $(44 \%)$, como agresividad proyectada sobre el otro. Todos los participantes muestran indignación, pero, en el ranking de los indignados, ocupan el primer lugar $\mathrm{Cu}$ yàs y Girauta, que, curiosamente, también ocupan el primer lugar en la expresión de empatía. 
Tabla 2. Ejemplo de trabajo con el corpus.

\begin{tabular}{|c|c|c|c|c|c|c|c|c|}
\hline Tertuliano & Tiempo & $\begin{array}{l}\text { Emoción } \\
\text { expresada }\end{array}$ & $\begin{array}{l}\text { Emoción } \\
\text { provocada }\end{array}$ & $\begin{array}{l}\text { Palabra/frase } \\
\text { emocionadora }\end{array}$ & $\begin{array}{l}\text { Ritmo y } \\
\text { entonación }\end{array}$ & $\begin{array}{l}\text { Expresión y } \\
\text { gesto }\end{array}$ & \begin{tabular}{|l|} 
Plano y \\
movimiento \\
cámara
\end{tabular} & Observaciones \\
\hline Sardà & 10.30 & Alegría & Entusiasmo & $\begin{array}{l}\text { Benvingut a la casa } \\
\text { del sobiranisme! }\end{array}$ & Enfáticamente & $\begin{array}{l}\text { Gestos } \\
\text { exagerados } \\
\text { de } \\
\text { bienvenida }\end{array}$ & Primer plano & $\begin{array}{l}\text { Haciendo un } \\
\text { simulacro de } \\
\text { spot publicita- } \\
\text { rio dirigiéndose } \\
\text { a Girauta }\end{array}$ \\
\hline Riba & \multicolumn{3}{|l|}{$\begin{array}{l}06.38 \\
\text { Ansiedad } \\
\text { Impaciencia }\end{array}$} & $\begin{array}{l}\text { Un moment, un } \\
\text { moment, Manel. Jo } \\
\text { he dit, jo he dit... }\end{array}$ & $\begin{array}{l}\text { Eleva el tono } \\
\text { de voz y habla } \\
\text { rápido }\end{array}$ & $\begin{array}{l}\text { Gesticula } \\
\text { nervioso }\end{array}$ & Primer plano & $\begin{array}{l}\text { Confrontación } \\
\text { con Cuyàs }\end{array}$ \\
\hline Mas & 38.40 & Indignación & Provocación & $\begin{array}{l}\text { Aquesta trampa que } \\
\text { has fet és enginyosa! }\end{array}$ & Tono intimista & $\begin{array}{l}\text { Aparece } \\
\text { divertido }\end{array}$ & Primer plano & \\
\hline Sardá & 40.55 & Sorpresa & Indignación & $\begin{array}{l}\text { L'entusiasme amb el } \\
\text { que es va viure en } \\
\text { determinats sectors } \\
\text { aquells anys des del } \\
\text { Constitucional!.. }\end{array}$ & $\begin{array}{l}\text { Lenta y } \\
\text { enfáticamente }\end{array}$ & $\begin{array}{l}\text { Gestos } \\
\text { histriónicos }\end{array}$ & \begin{tabular}{|l|} 
Plano de dos \\
tertulianos \\
para \\
subrayar que \\
ambos ríen \\
\end{tabular} & \\
\hline Sanchis & 41.42 & Sorpresa & Complicidad & $\begin{array}{l}\text { A més, són } 11 \\
\text { persones! }\end{array}$ & $\begin{array}{l}\text { Interrumpe en } \\
\text { voz baja }\end{array}$ & & $\begin{array}{l}\text { No aparece } \\
\text { en pantalla }\end{array}$ & \\
\hline Girauta & 43.20 & Autosuficiencia & Indignación & Va pactar... & Ritmo lento & $\begin{array}{l}\text { Gesticulación } \\
\text { controlada }\end{array}$ & Primer plano & \\
\hline
\end{tabular}

Por otra parte, la tranquilidad (26\%) aparece muy decantada hacia el autocontrol $(80 \%)$, es decir, se trata de una emoción discursiva aprendida, orientada a aparecer superior delante del otro, más que hacia la calma (20\%). Sanchis y Girauta son los más autocontrolados y el único tertuliano que no muestra calma ni autocontrol es Sardà.

En cuanto a la empatía, aparece en tercer lugar (13\%), conectada con las técnicas de seducción. Es el „Yo te entiendo, podemos cooperar, aunque no pensamos lo mismo.“. Cuyàs y Girauta son sus principales usuarios, aunque ya hemos dicho que también son los más indignados, pero todos los participantes muestran empatía en un momento u otro hacia sus aliados o hacia sus oponentes.

La ansiedad (10\%) parece ser la emoción que más esconden la mayoría de tertulianos: Cuyàs, Mas, Sanchis y Girauta. En cambio, Riba y, sobre todo, Sardà, se muestran ansiosos en muchos momentos.

La alegría (6\%), la tristeza (5\%) y la sorpresa (3\%) son tres emociones con muy poca presencia. De entre todos los participantes, quien más expresa estas emociones es Sardà.

Con relación a la traza semiológica de las emociones, la integran principalmente las exclamaciones, las palabras axiológicas y las palabras neutras, pero emotivas en el contexto. Todos los tertulianos hacen uso de las mismas, aunque la selección varíe, según la personalidad emotiva y el registro del participante.

La entonación emocional se caracteriza por el énfasis en las fórmulas interrogativas, a menudo retóricas, y las exclamativas. Todos los tertulianos las utilizan.

El ritmo emocional se caracteriza por la ralentización, a veces con segmentación silábica y el alargamiento vocálico. Sardà y Riba son los que más lo usan.

También se dan las repeticiones de segmentos, que tanto pueden ser sólo palabras como sintagmas enteros. Generalmente, denotan impaciencia, enojo, o ganas de imponerse. Cuyàs, Sardà y Riba son los que más utilizan esta estrategia.

La imagen de un tertuliano, durante su turno de palabra, suele expresar las mismas emociones que el discurso verbal. Por lo tanto, imagen y palabras mantienen 
una relación de redundancia. En cambio, cuando la cámara se detiene en uno de ellos mientras escucha el discurso de otro tertuliano puede mostrar también esta relación de redundancia, si manifiesta adhesión emocional, pero si la imagen expresa emociones no compartidas o divergentes con las del hablante, y somos conocedores de la diferencia de punto de vista entre ambos participantes, la relación establecida entre imagen y palabras es complementaria.

La gran mayoría de expresiones emotivas están marcadas por el contexto mediático, son de carácter intencional, y se utilizan como efectos de discurso. Palabras, rasgos prosódicos e imágenes (redundantes o complementarias), contribuyen a manifestarlas.

Es comprensible, pues, que la indignación sea la más presente en la primera tertulia y, en general, tiene un papel principal en los programas de debate, de determinadas tertulias o de talk shows. El autocontrol y la empatía, que ocupan el segundo y el tercer lugar en el ranking, son emociones de „saber estar en grupo“, y sirven para suavizar la indignación y destensar la situación.

También parece lógico que la ansiedad aflore todo en la pugna por el turno de habla y para aparecer legitimado discursivamente. A veces, la gestualidad muestra más esta ansiedad que las propias palabras utilizadas. En cambio, la alegría, tristeza, y sorpresa son evitadas por la mayoría de los tertulianos, quizás porque no están propiciadas por el contexto mediático, aunque sepamos que algunos las utilizan para obtener la adhesión de la audiencia, sobre todo cuando la argumentación discursiva no es suficiente sólida.

La segunda tertulia presenta una característica diferente respecto de la primera sobre la explotación que se hace de las emociones. Los tertulianos muestran unas emociones de estado cualitativo claramente positivas (64\%), pero esconden una intención muy diferente porque finalmente la presencia de las emociones positivas de tipo racional es sólo del 34\%. Por lo tanto, se invierten los resultados entre las emociones afectivas y racionales. Esta bipolarización en los resultados se repite con la indignación (que pasa del $8 \%$ al 47\%), la ansiedad (del 25\% al 8\%), la tristeza (del $3 \%$ al $11 \%$ ) y la calma (del $50 \%$ al $3 \%$ ), mientras que la alegría se mantiene en un porcentaje bajo en ambos casos (3\%) y la sorpresa aparece sólo tres veces y de la mano de una única persona, Núria Farré. Tal como habíamos visto en la primera tertulia, la alegría y la sorpresa son emociones poco representadas.

La emoción que tiene una presencia más alta en la segunda tertulia es la calma, ya que aparece en un 50\% de las ocasiones, la segunda emoción más común es la ansiedad $(25 \%)$ y las dos juntas, pues, llegan al $75 \%$. De las emociones más residuales, la que más aflora dentro de las de estado cualitativo es la empatía. Por todo ello se puede ver que hay buena relación entre los tertulianos, ya que no se enfrentan entre ellos ni personalmente ni por grupos.

Con respecto a la cámara en la segunda tertulia, debemos decir que pasea mucho la mirada y que no se queda estancada en ningún primer plano sin que exista un objetivo expreso. La cámara se abre mucho en momentos de consenso general, especialmente cuando se muestran emociones claras y más aún si son compartidas. Se enfoca al hablante cuando tiene la palabra, y si la cámara descansa en otros tertulianos es para revelar si están de acuerdo con los enunciados del hablante, para mostrar la actitud del tertuliano que escucha una réplica a sus palabras o para enseñar la reacción 
de algún miembro de la mesa cuando desvela claramente una emoción. Se observa algún travelling en las ocasiones en que hay un cierto consenso en la mesa, a menudo porque se enseña que se crea empatía entre los hablantes que se muestran de acuerdo sobre algún comentario. De este modo la cámara envuelve el grupo y lo presenta a los espectadores como un conjunto cohesionado. Hay algún picado y contrapicado que se acerca a la mesa, que acompaña a los comentarios cuando se inicia un tema o cuando un punto de vista genera atención entre los participantes.

En general, la entonación es contenida, más que en la primera tertulia. En este mismo sentido hay menos exclamaciones y no aparecen nunca sin una explicación añadida. Los hablantes se muestran más distendidos cuando explican la situación política en tono de broma. Incluso hay poca gestualidad que acompañe a las exclamaciones: movimientos de manos y en algún caso concreto de brazos, pero sin sobrepasar los hombros. Tampoco hay aproximaciones físicas entre los hablantes cuando muestran empatía o cuando disienten, en un intento de mantener la cordialidad, en general se mantienen distendidos, pero sin apoyarse en la mesa, salvo Manchón y Riba.

Les trazas semiológicas descansan en palabras neutras (,vecinos de una escale-

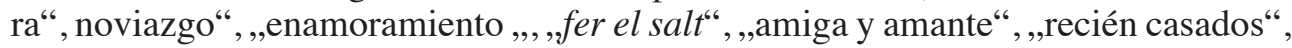
„,ball de rams", „uniones“, "en el minuto 92 marcamos“, „,cortafuegos“) pero que fuera del contexto donde generalmente aparecen y aplicadas al mundo de la política permiten inferir una lectura emocional. Por otro lado, cabe decir que los tertulianos no traspasan nunca la frontera de la broma.

\section{Conclusiones}

Para dar respuesta a los objetivos marcados al inicio presentamos a continuación la respuesta a las dos preguntas que nos habíamos planteado:

1. La selección de emociones está condicionada por el contexto mediático donde se genera el debate televisivo estudiado: los tertulianos quieren aparecer legitimados y su intención es la de llegar a ganarse la audiencia tanto la que se adscribe al grupo de sus posicionamientos políticos como a los que son de un signo contrario. Sobre todo en la segunda tertulia hemos observado que el juego entre las emociones expresadas e intencionadas logra un propósito diferente. Los rasgos prosódicos de los enunciados tienen un papel muy importante, debido a que ciertas afirmaciones van acompañadas de un juego emocional intencionado para que el tertuliano y sus ideas puedan llegar mejor a la audiencia, que también está formada por el resto de tertulianos. El papel del realizador y sus decisiones sobre cómo la cámara mostrará este entramado de identidades emocionales y enunciados puede llegar a afianzar o modificar la percepción de los espectadores, los cuales para enriquecer sus conocimientos con lo que se dice y obtener una gratificación eudaimónica deben tener una actitud que les permita activar las representaciones sociales que comparten y que gracias a la memoria pueden recordar. 
Los tres aspectos relacionados, las emociones de los tertulianos, los rasgos prosódicos de sus enunciados y el movimiento de la cámara, permite reforzar las identidades emotivas de los tertulianos y las decisiones discursivas que toman para comunicar unas ciertas emociones que puedan ser comprendidas por la audiencia sin tener que sobrepasar los límites que el medio y el tipo de programa impone.

2. La emocionalización del discurso confiere una identidad propia a cada tertuliano. De este modo, en cuanto a las identidades emocionales de los participantes de la primera tertulia:

- Cuyás administra las emociones, como tertuliano experto que es: se indigna, pero al mismo tiempo, busca empatía; también muestra calma y autocontrol en el discurso, aunque se remueva en la silla y que la expresión de su rostro revele a veces cierta inquietud y nerviosismo.

- Girauta tien un discurso que es a la vez indignado y autocontrolado. Intenta ser empático, sobre todo con Sardà, con el que comparte algunas creencias. En alguna ocasión, cuando deja de controlarse, se muestra triste, alegre o sorprendido.

- Mas expresa pocas emociones: sólo la indignación, teñida menudo de ironía, y el autocontrol, que aparecen en igual proporción. También intenta ser empático, incluso con los debatientes oponentes, como Girauta.

- Riba manifiesta ansiedad e indignación, y busca empatía con Mas, Sardà y Girauta.

- Sanchis es el tertuliano del enfrentamiento, pero a partir del autocontrol. Su discurso es contundente y bien argumentado. No pierde la calma y tiene la réplica siempre a punto.

- Sardà tiene el discurso más emotivo. Manifiesta indignación (pero evita la confrontación) y un alto grado de ansiedad; alegría y tristeza por un igual; también sorpresa, habitualmente teñida de decepción. No aparece calmado ni seguro en ningún momento, muestra su tono afectivo (con dudas de si es intencional).

En la segunda tertulia:

- Farré es la tertuliana que más emociones positivas exhibe en primera instancia (91\%), pero sabe reconducir la situación hasta llegar al $74 \%$ de emociones negativas racionales. Se muestra segura (57\%) y no le cuesta compartir la mirada con el resto de tertulianos. 
- Manchón reparte las emociones cualitativas no intencionales entre las negativas (52\%) y las positivas (48\%) y los porcentajes no varían mucho de las categorías intencionales o racionales (negativas $40 \%$ y positivas, $60 \%$ ). Dentro de las negativas cualitativas, la que más a menudo manifiesta es tensión (43\%). Aparece ante la cámara con se cuerpo estirado y la mirada severa, pero busca con la proximidad del cuerpo la comprensión de Riba, que se sienta a su lado.

- Riba, si bien el 71\% de las emociones no intencionales que manifiesta son positivas, sabe equilibrar más que ningún otro tertuliano las emociones intencionales entre positivas (49\%) y negativas (51\%). La seguridad es la emoción cualitativa que más veces está presente en su discurso (51\%). Difícilmente se podría aseverar que se refleja un cambio en la actitud en este periodista entre las dos tertulias, ya que las emociones negativas siguen estando presentes, aunque la composición de la mesa y el momento político distinto dejar entrever algunos matices.

- Serrano es el profesor universidad al que todo el mundo respeta y permite que termine la presentación de los argumentos sin obstáculos, tal vez sólo con algunas expresiones que corroboran su relato. Las emociones cualitativas que más manifiesta son la seguridad $(36 \%)$ y el autocontrol (20\%).

- Romeu equilibra mucho las emociones positivas (46\%) con las negativas $(54 \%)$ de carácter no intencional, pero las reconvierte cuando llega al ámbito intencional $(80 \%$ de negativas y $20 \%$ de positivas. Al mismo tiempo las emociones cualitativas más presentes son la tensión (31\%) que sabe manifestar con seguridad (20\%).

Los resultados citados corroboran la hipótesis de partida que cada tertuliano aparece ante la cámara con una identidad emocional bien definida que los espectadores captan dentro de su voluntad de contemplar el espectáculo televisivo de las tertulias. La composición de cada mesa, así como el momento político, puede llegar a incidir en los comportamientos de los tertulianos en los debates, y se manifiesta claramente el nerviosismo de la primera tertulia cuando parecía que iba a ser imposible que los partidos llegaran a consensuar una pregunta para la consulta que finalmente se realizó casi un año después, el 9 de noviembre de 2014. En cambio, en el segundo debate, plana la tranquilidad (excepto en Manchón que muestra mucha tensión durante todo el debate), ya que la posible repetición de elecciones en el Estado español no se observa como un problema propio y esa percepción tiende a rebajar la tirantez del ambiente. 


\section{Referencias bibliográficas}

Abric (1984). On the System of Representations in an Artificial Social Situation. En R. M. Farr y S. Moscovic, (eds.). Social Representations (pp. 239-253), Cambridge and Paris: Cambridge University Press y Editions de la Maison des Sciences de l'Homme.

Margarida Bassols y Anna Cros (2014). Conferencia: Les identitats (discursives) a Catalunya a través d'un magazín televisiu. Jornada identitat(s) a Catalunya. Llengua i Mèdia e Institut de la Comunicació, UAB, 8 de octubre de 2014.

Bassols, M., Cros, A., y Torrent,A. M. (2013). Emotionalization In New Television Formats of Science Popularization. Pragmatics, 23(4), 605-632.

Bisquerra, R. (2003). Educación emocional y competencias básicas para la vida. Revista de Investigación Educativa, 21(1), 7-43.

Bisquerra, R. (2006). Educación emocional y bienestar. Madrid: Praxis

Bucholtz, M., y Hall, K. (2010). Locating identity in language. En C. Llamas y D. Watt (eds.) Language and identities (pp. 18-28). Edimburg: Edinburgh University Press.

Charaudeau, Patrick (2009). "Identité linguistique, identité culturelle: une relation paradoxale". Recuperado de: http://www.patrick-charaudeau.com/IMG/ pdf/2009_b_Id-_culturelle_Perpignan_.pdf.

Charaudeau, P. (2011). Las emociones como efectos de discurso. Versión, 26(junio). La experiencia emocional y sus razones, 97-118, Mexico: UAM.

Charaudeau, Patrick (2008). La médiatisation de la science. Clonage, OGM, Manipulations genètiques. Bruxelles: De Boeck.

Compte, C. (2009). L'image en mouvement. La médiatisation du regard. Paris: Lavoisier.

Lazarus, Richard S. (1993). From psychological stress to the emotions: A History of changing outlooks. Annual Review of Psychology, 44, 1-21.

Ortony, A., Clore G. L., and Collins, A. (1988). The Cognitive Structure of Emotions. Cambridge, UK: Cambridge University Press.

Roth F.S., Weinmann C., Schneider F.M., Hopp F.R. y Vorderer P. (2014). Seriously entertained: Antecedents and consequences of hedonic and eudaimonic entertainment experiences with political talk shows on TV. Mass Communication and Society 17(3), 379-399.

Russell, J. A. (1980). A Circumplex Model of Affect, Journal of Personality and Social Psychology, 39(6), 1161-1178.

Squire, C. (2001). The public life of emotions. International Journal of Critical Psychology March, 1, 27-38.

Tajfel, H. (1981). Human groups and social categories. Cambridge: Cambridge University Press.

Tresserras, J. M. (2013). Debat: Llengua, mitjans i identitat. Universitat Autònoma de Barcelona. 15 d'octubre de 2013.

Van Dijk, T. A. (1998). Ideology. A Multidisciplinary Approach. London: SAGE Publications.

Walton, D. (1992). The Place of Emotion in Arguments. Pennsylvania: The Pennsylvania State University Press. 
Wirth, W., y Schramm H. (2005). Media and Emotions. Communication Research Trends". Communication Research Trends Volume, 24(3), 1-39. Recuperado de http://cscc.scu.edu/trends/v24/v24_3.pdf. 